\title{
Head Impact Severity Measures for Small Social Robots Thrown During Meltdown in Autism
}

\author{
Ahmad Yaser Alhaddad ${ }^{1,2}$ (D) John-John Cabibihan ${ }^{1}$ (D) Andrea Bonarini $^{2}$ (D)
}

Accepted: 28 September 2018 / Published online: 2 November 2018

(c) The Author(s) 2018

\begin{abstract}
Social robots have gained a lot of attention recently as they have been reported to be effective in supporting therapeutic services for children with autism. However, children with autism may exhibit a multitude of challenging behaviors that could be harmful to themselves and to others around them. Furthermore, social robots are meant to be companions and to elicit certain social behaviors. Hence, the presence of a social robot during the occurrence of challenging behaviors might increase any potential harm. In this paper, we identified harmful scenarios that might emanate between a child and a social robot due to the manifestation of challenging behaviors. We then quantified the harm levels based on severity indices for one of the challenging behaviors (i.e. throwing of objects). Our results showed that the overall harm levels based on the selected severity indices are relatively low compared to their respective thresholds. However, our investigation of harm due to throwing of a small social robot to the head revealed that it could potentially cause tissue injuries, subconcussive or even concussive events in extreme cases. The existence of such behaviors must be accounted for and considered when developing interactive social robots to be deployed for children with autism.
\end{abstract}

Keywords Social robots $\cdot$ Safety $\cdot$ Autism $\cdot$ Meltdown $\cdot$ Head impact

\section{Introduction}

In the last few decades, robotics research has witnessed significant changes in the traditional paradigm as it has shifted to cover new areas, such as entertainment, transportation, space, healthcare, and others [102]. Robots are now being considered to be used in many applications (e.g. rehabilitation and elderly care) that require direct physical human-robot interaction [37,102].

Autism spectrum disorder (ASD) is a condition that is diagnosed during childhood and affects neurodevelopment [120]. Previous studies have shown that children on the spectrum have strong interest in technology, such as computer applications [48], virtual environments [87], and robots $[16,98]$. There has been a growing interest in the clinical

John-John Cabibihan

john.cabibihan@qu.edu.qa

1 Department of Mechanical and Industrial Engineering, Qatar University, Doha 2713, Qatar

2 Department of Electronics, Information and Bioengineering, Politecnico di Milano, Piazza Leonardo da Vinci 32,

20133 Milano, Italy use of robots to assist in the therapy of children with ASD $[10,28,52]$. The usage of technology, especially robotics, for ASD therapy opens many possibilities in the early intervention for children with ASD, and toward more personalized therapy $[90,91]$. The application of robots for intervention provides many options and flexibility as robots can be used as an intervention tool to facilitate the therapeutic session, as a co-therapist with turn-taking with the main therapist or as a sole therapist $[10,29]$.

There has been a growing concern pertaining to the rise at an unprecedented rate of ASD among children. For example, the pervasiveness rate of ASD was found to be 1 out of 45 in the United States [118] while in the United Kingdom, the estimate was 1 out of 100 [39]. Due to the diverse nature of ASD, the manifestation of behaviors among children on the spectrum varies greatly in their degree. Children with ASD face lifelong impairments in social interaction, communication, and the exhibition of restricted interests or behaviors [5]. Furthermore, children face a multitude of daily behavioral challenges as compared to neurotypical children $[23,26]$. Intervention, especially during the early years, seems to play a significant role in the treatment, or at least in the mitigation 


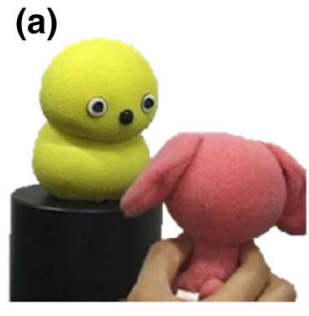

(e)

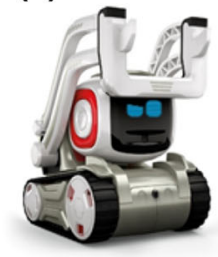

(b)

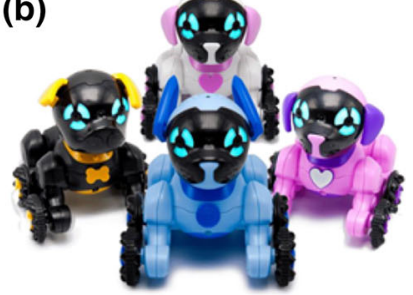

(f)

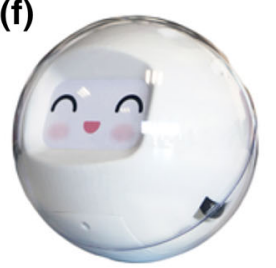

(c)
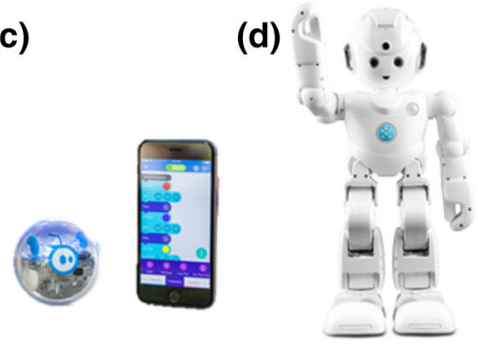

(g)

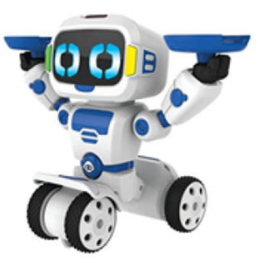

Fig. 1 Some of the robots that have been considered or have the potential for ASD intervention: a Keepon, a yellow snowman-like robot [68]. b Chippies, a pack of playful puppies (With kind permission from WowWee Group Ltd). c SPRK+, a ball robot (With kind permission from Sphero). d Lynx, a humanoid robot companion (With kind per- mission from UBTECH). e Cozmo, an interactive forklift-inspired robot (With kind permission from Anki). f Leka, an autonomous ball-like robot (With kind permission from Leka Inc). g Tipster, an interactive toy robot (With kind permission from WowWee Group Ltd)

manifestation of challenging behaviors. Children with ASD often exhibit a variety of stereotypical behaviors that are often impulsive and aggressive. Such behaviors could be a response to an unwanted stimulus or as a result from a failed emotional regulation [77].

The rapid evolution of technology has sparked a global interest in robotics and their prospective applications. The International Federation of Robotics (IFR) [57] has predicted that the number of entertainment robots, such as toy robots, personal edutainment robots, and multi-media robots, will rise to 11 million units by 2019 . This dramatic increase in the number of robots, especially the ones in close proximity with humans, has implications on safety that emphasize the need for standardization. Some of the standards that were established were ISO 10218 [58,59], which is concerned with safety in industrial robots; ISO/TS15066 [62], which is related to collaborative industrial robots; and ISO 13482 [60], which is related to personal care robots. Currently, there is no safety standard for social robots or toy robots.

One of the earliest works concerning safety and harm quantification with robotics introduced the human pain tolerance as an indicator for potential risks [114]. In another work, the simulation of impact tests of an industrial robot on a crash test dummy using Finite Element Method (FEM) was proposed and demonstrated to assess safety [84]. In later works, actual crash test dummies have been used in impact tests using industrial robotic arms $[44,46]$. Various safety indices, such as for the head, chest, and neck, have been used in the evaluation of safety and potential injury levels due to impacts. To date, limited studies have been conducted on 
Fig. 2 Different forms of challenging behaviors that are exhibited by children with ASD $[35,66,72,75]$

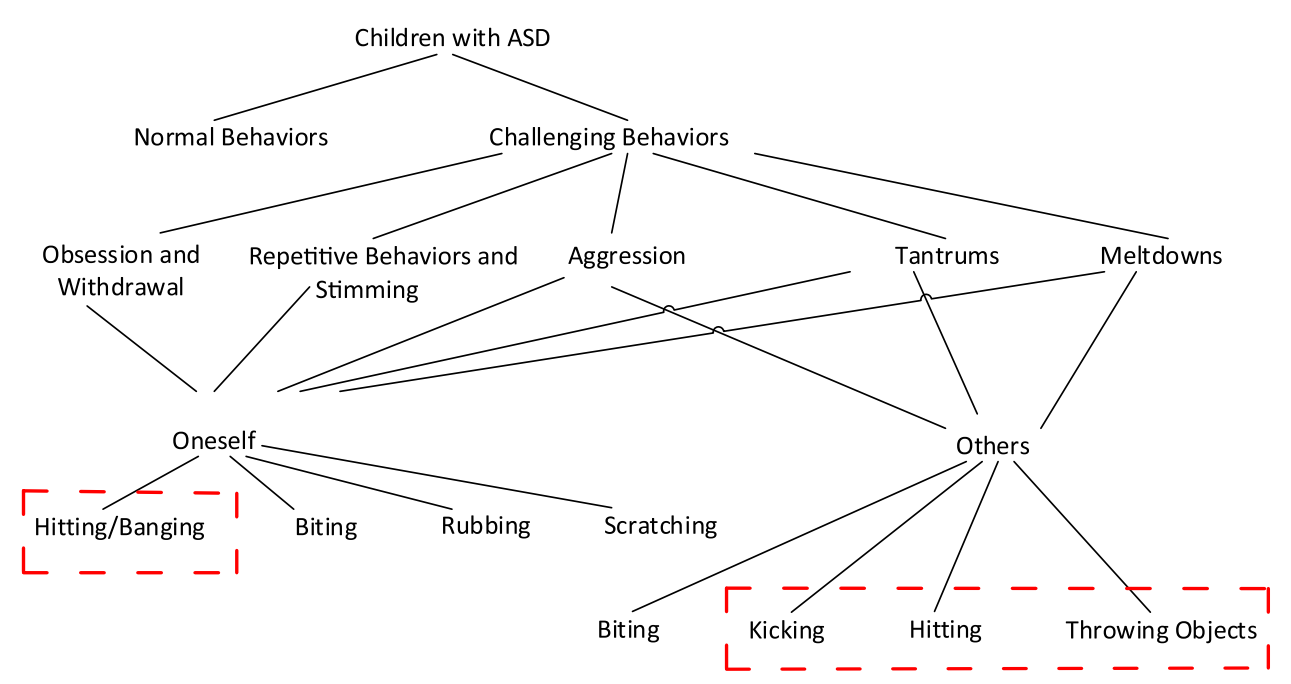

safety in social robotics, especially pertaining to the safety of children with ASD [38,50,109].

The objective of this study is to quantify the harm levels based on severity indices for one of the identified potentially harmful scenarios that might arise between a child and a social robot due to the manifestation of challenging behaviors. This paper is organized as follows. Section 2 describes the epidemiology of challenging behaviors and the potential risks with robots. Section 3 describes the harm quantification and relevant severity indices. Section 4 provides the materials and methods. Section 5 describes results, which are then discussed in Sect. 6. Section 7 concludes the study.

\section{Challenging Behaviors in Children with ASD}

\subsection{Overview}

Individuals on the spectrum are unique and complex in their dispositions and in their manifestation of ASD. Autism affects such individuals and causes a lot of deficits and challenges in their communication skills, interactions with others, behaviors, sensory inputs perception, and social life [23]. Furthermore, they exhibit self-stimulatory behaviors, perfectionist tendencies, meltdowns, and delayed echolalia [30]. Children diagnosed with ASD tend to exhibit more challenging and aggressive behaviors than their neurotypical peers (Fig. 2). For example, those with perfectionist tendencies and emotional regulation deficiencies have shown higher level of aggressive behavior, anxiety, and depression $[4,6]$.

Frustration is another contributing factor toward the exhibition of more challenging behaviors. Children with ASD might face frustration when being exposed to new unpredictable, overwhelming, and noisy environments as that found in hospitals [66,97]. In addition, such environments are rich in stimuli that might overload their body's senses, and that would make meeting their needs even harder due to the increased struggle with the new environmental changes [82,97]. Challenging behaviors take different forms, such as withdrawal, repetitive and stereotypical habits, aggression against others, self-injury, tantrums, meltdowns, and property destruction $[66,72,75]$. Not only such behaviors pose risks on the children themselves, but also pose a lot of risks on others around them, such as other children, nurses, patients, caregivers, parents, and family members $[66,88]$.

\subsection{Epidemiology of Challenging Behaviors}

Among all the children with developmental disabilities, challenging behaviors and anxiety problems seem to have higher prevalence rate among children with autism [32,42]. Those with more severe ASD have showed higher rate of challenging behaviors as compared to those with less ASD severity [76,81]. Furthermore, studies have shown that even infants or toddlers that are diagnosed with ASD do exhibit challenging behaviors at a higher rate compared to their neurotypical counterparts $[35,69]$. Due to difficulties in using proper communication to satisfy their needs, children with autism might turn to challenging behaviors as a form of communication to express themselves [55].

The pervasiveness of challenging behaviors among individuals with autism is relatively high. One study surveying 222 children reported a $50 \%$ occurrence rate while another study surveying 32 adults reported a rate of $69 \%$ [7,13]. A more recent study with a larger sample size of 1,380 children has reported a high aggression prevalence rate of $68 \%$ against caregivers and $49 \%$ against others [67]. The majority of the previous studies have reported the occurrence of at least one or more challenging behaviors among at least half of the individuals with ASD [35]. The existence of such 
behaviors has many implications on those providing treatments and services to individuals with ASD [55].

\subsection{Robots and Potential Risks}

Technology offers a lot of potential to therapeutic sessions, such as, but not limited to, independent learning, individualizing, motivation, reinforcement, social and communicative skills practice, hands-on learning, and others [31]. The advancement in several Artificial Intelligence (AI) fields has enabled robots to function independently and more naturally for effective social interactions. Social robots differ from typical toys in many ways, such as the way they engage people at an interpersonal level to achieve positive outcomes in different domains [14]. Furthermore, social robots should be able to convey emotions, form social relationships, demonstrate personality, use natural communication cues, and to understand their social partners [49]. Child-robot interactions are characterized beyond traditional toys by the form of a robot's embodiment, the interface of communication, two-way interaction, and the robot's adaptability to the child $[24,36]$.

Children interacting with social robots are prone to touching the robot. In some cases, they might show aggression toward the robot $[1,11,107]$. This requires that the existing design guidelines must ensure the safety of the children and the physical integrity of the robot, especially during meltdowns $[1,16,17]$. While some of the existing robots could meet many of the therapy objectives, they are still not adequate enough to be used with some of the children on the spectrum who may exhibit hyperactivity and aggression [53]. The majority of the social robots used in the literature are just prototypes, not commercially available, and have yet to find their ways into therapy sessions or special needs schools [52]. Hence, the exposure to such technology is still very limited worldwide and the need to identify potential safety issues arises. The wide adoption of social companions and smart toys would introduce some concerns and ethical considerations that must be addressed early on [22,24,74,100].

The occurrence of challenging behaviors, such as kicking objects, throwing objects at others, banging on objects, and harming oneself by hitting [75], when a robot is present increases the chances of potentially risky scenarios (Fig. 3). Depending on the size of the social robot being used, the magnitude of potential risks might change accordingly. For instance, kicking a large robot will inflict an initial harm to the kicker and secondary damage on others in case of the robot falling down on them. On the other hand, kicking a small robot might affect others and cause harm. Another challenging behavior that could inflict harm on others is throwing, especially in the case of small and light robots. The child could use the small robot involuntarily as an object to be thrown to others. Self-inflicted harmful behaviors, such as banging and hitting, could be increased with the presence of

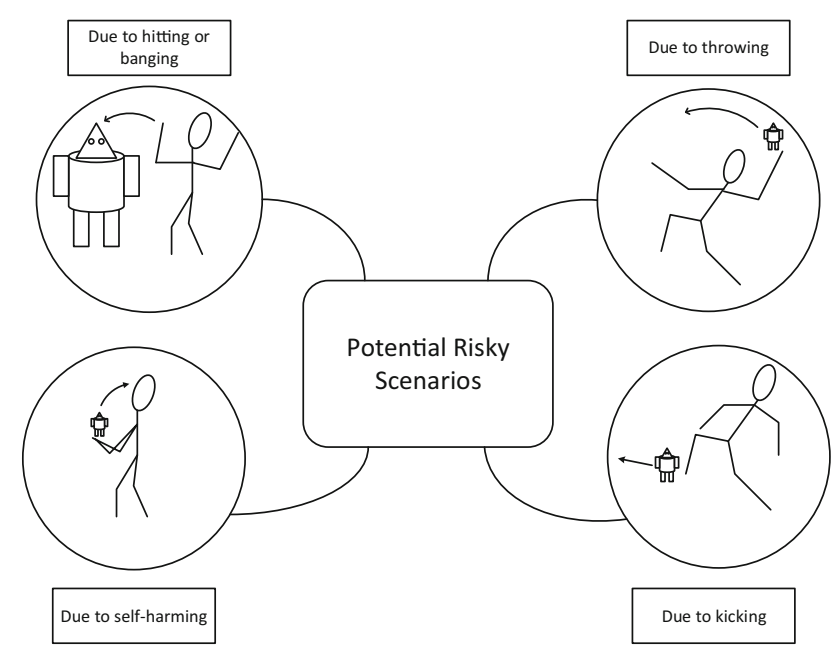

Fig. 3 The identified possible risky scenarios that might occur between a child and a social robot due to some of the challenging behaviors

a robot as it can be used by the child. All the aforementioned scenarios must be accounted for when designing robots and solutions to mitigate them must be investigated.

\section{Quantifying Harm}

\subsection{Overview}

The human head is susceptible to traumatic brain injury (TBI) when it is receiving blows or bumps, or when subjected to impacts with projectiles, such as a baseball [12]. TBI is categorized as either being mild or severe, and could cause permanent disability or in severe cases, death. The most occurring type of mild TBI is concussion. It is not considered life threatening. However, the results on the affected individual can be serious [83]. In the United States and in 2013 alone, a total of 2.8 million cases (i.e. 50,000 deaths, 282,000 hospitalizations, and 2.5 million emergency department visits) of TBI have been reported with falls being the lead cause followed by getting struck by or against an object [108]. Furthermore, it has been reported that 1 in 5 cases of TBI occurred among children (age $<15$ years old). TBIs among young children may impair the neurological development and cause a multitude of challenges, such as depression, attention deficit hyperactivity disorder, and in attaining academic achievements $[2,3,89,116]$.

Throwing objects, especially in the case of small robots, pose a great risk to the head and needs to be quantified. The objective of this study is to simulate objects being thrown at the head to quantify harm levels. Hence, this section describes the related studies and relevant severity indices. 


\subsection{Related Impact Tests}

Laboratory settings using anthropomorphic test dummies (ATD) are typically used to simulate potentially dangerous scenarios to evaluate the possible harm to a human, such as that used in car crash tests. Furthermore, similar setups have been used to quantify harm due to impacts in some sports and to evaluate protective gears, such as helmets $[78,85,115]$. One study used similar settings to assess the influence of taekwondo kicks and the peak velocity of the foot on the dynamics of the head [34]. In that study, a crash test dummy head was secured to an aluminum frame and it was used as a target for the kicks performed. The dummy head was equipped with an accelerometer to measure the dynamics of the head (i.e. changes in acceleration) as it was being hit by the participants. The data generated was used to assess the potential of concussion based on the head injury criterion (HIC).

Similar studies were conducted in industrial robots to quantify the potential harm due to different possible impact scenarios between a human and a robotic arm. For example, studies have conducted impact tests of a manipulator to a dummy at a standard automobile crash test facility [44-46]. In such studies, impacts by robotic arms using flat surface impactors were performed against a standard crash test dummy in three regions (i.e. head, chest, and neck). The potential of injury or harm levels were evaluated based on the respective severity index or indices for each region. The evaluations were based on varying some robotic-dependent variables, such as mass and velocity, and their relation on the resultant severity indices. In some studies, low-cost body part models, such as using a head model or an arm model, and low-cost sensors were considered and used to carry out experimental tests to evaluate human-robot impacts [25,45].

\subsection{Severity Indices}

Severity indices are associated with injury scaling, such as the Abbreviated Injury Scale (AIS) [40]. AIS is a tool that provides a simple way to grade the observed injury based on a scoring criteria (Table 1). AIS, together with various severity indices, give an estimation of the potential for an injury and its respective severity.

The investigation in this study was limited to the head, hence, only relevant head indices, namely, head injury criterion (HIC), 3 ms criterion, peak linear acceleration, impact forces, and tissue injuries, are summarized.

\subsubsection{Head Injury Criterion}

Head Injury Criterion (HIC) is one of the most commonly used severity indices to measure the possible injury to the head in many applications, such as in vehicles and in sports
Table 1 Abbreviated Injury Scale (AIS) and the corresponding injury classification

\begin{tabular}{ll}
\hline AIS score & Injury classification \\
\hline 1 & Minor \\
2 & Moderate \\
3 & Serious or severe, but not life threating \\
4 & Severe and life threating \\
5 & Critical and uncertain survivial \\
6 & Unsurvivable \\
\hline
\end{tabular}

Table 2 The values of population mean $\mu$ and standard deviation $\sigma$ corresponding to different scores of the Abbreviated Injury Scale (AIS)

\begin{tabular}{lll}
\hline AIS score & $\mu$ & $\sigma$ \\
\hline 2 & 6.96352 & 0.84664 \\
3 & 7.45231 & 0.73998 \\
4 & 7.65605 & 0.60580 \\
\hline
\end{tabular}

[110]. HIC is defined as:

$H I C=\left(t_{2}-t_{1}\right)\left[\frac{1}{\left(t_{2}-t_{1}\right)} \int_{t_{1}}^{t_{2}} a(t) d t\right]^{2.5}$

where $a(t)$ is based on the resultant acceleration of the head and measured in terms of gravitational acceleration $(\mathrm{g}=$ $9.81 \mathrm{~m} / \mathrm{s}^{2}$ ) and $\Delta t=t_{2}-t_{1}$ is the duration of the impact considered in calculating the resultant HIC. The two most commonly used durations to evaluate the severity of injury to the head are $36 \mathrm{~ms}$ and $15 \mathrm{~ms}$. Throughout this study, the 36 ms duration only will be used.

The HIC standard is converted to a corresponding AIS based on the following relation [70]:

$p($ head injury $)=\phi\left(\frac{\ln \left(H I C_{36}\right)-\mu}{\sigma}\right)$

where $\phi$ is the cumulative normal distribution, and $\mu$ is the population mean, and $\sigma$ is the standard deviation (Table 2). These values were originally specified for a test dummy head, hence, they will only be used for comparison purposes. At a particular HIC value, the probability of injury occurrence differs between each of the AIS scores (Fig. 4).

\subsubsection{The 3 ms Criterion}

This criterion requires that the maximum mean value over a $3 \mathrm{~ms}$ duration of the resultant head acceleration is less than a certain threshold when there is no hard contact (Fig. 5). This criterion is used as part of the regulations pertaining to the safety of occupants in vehicles and in helmet testing [99]. 


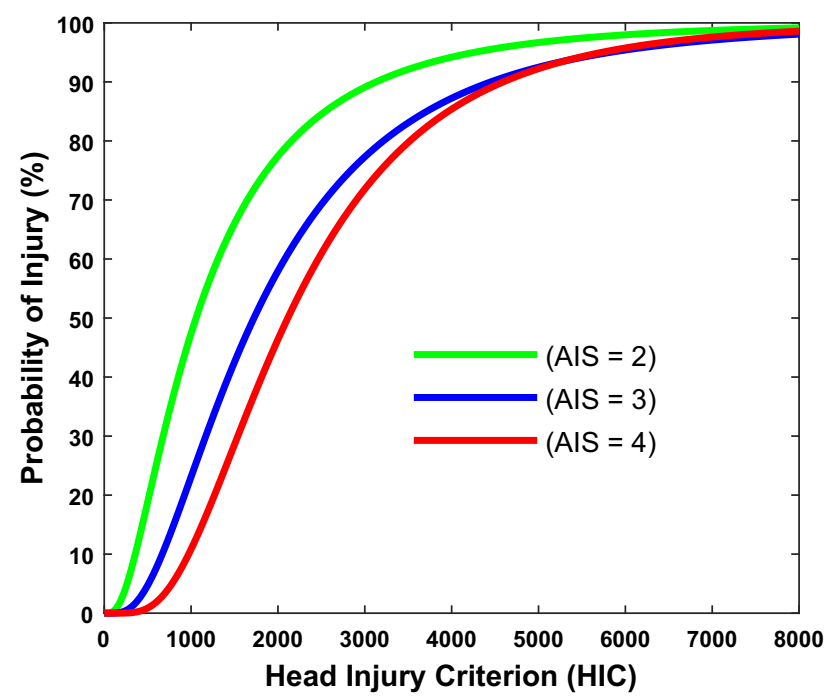

Fig. 4 The relationship between the head injury criterion (HIC) and the probability of injury according to different abbreviated injury scales (AIS) [70]

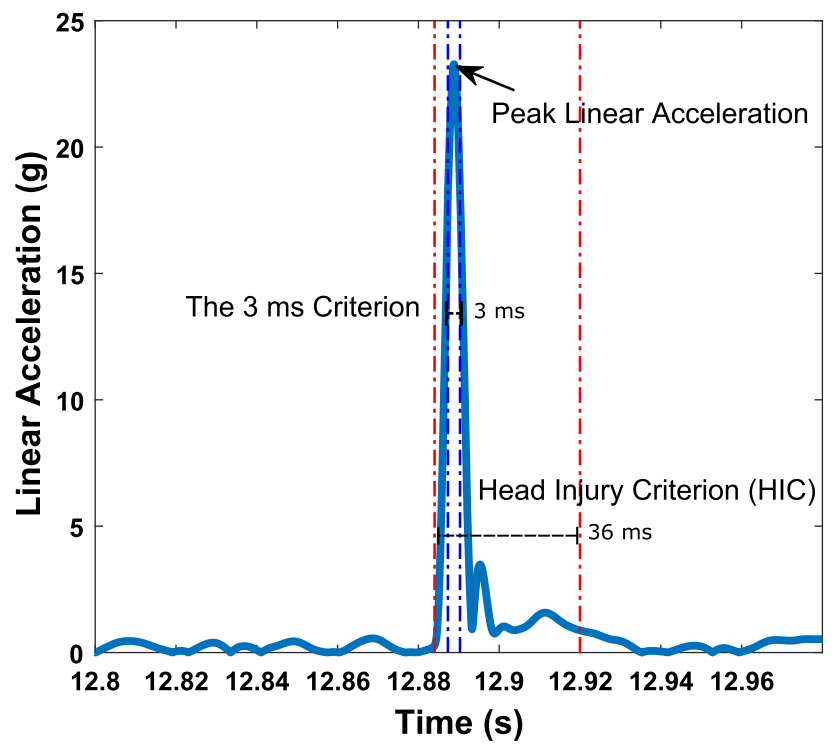

Fig. 5 Sample of the generated linear acceleration data demonstrating the durations of both the head injury criterion (HIC) and the $3 \mathrm{~ms}$ criterion. Also shown is the instance of peak linear acceleration that was considered in the data analysis

The European National Car Assessment Protocol (Euro NCAP) states that the thresholds for $3 \mathrm{~ms}$ criterion for a child occupant should not exceed $60 \mathrm{~g}$ in case of frontal impact and $60 \mathrm{~g}$ in case of side impact [33].

\subsubsection{Peak Linear Acceleration}

Peak linear acceleration has been used as one of the biomechanical measures for head impact to investigate its association with concussion events [41,94]. A study investigating the head impact exposure in youth football has reported linear accelerations due to impacts anywhere in the range of $10 \mathrm{~g}$ to $111 \mathrm{~g}$ [117]. While that study did not report the occurrence of any concussions, it is believed that concussions could occur within that range based on the reported football-related concussions [8]. One study based on a finite element head model validated from field collisions has estimated a probability of mild TBI to be $25 \%, 50 \%$, and $80 \%$ corresponding to maximum accelerations of $66 \mathrm{~g}, 82 \mathrm{~g}$ and $106 \mathrm{~g}$, respectively [119]. One study has reported the occurrence of a concussive event at a relatively low linear acceleration value of 31.8 $\mathrm{g}$ [80]. Some of these studies did not report the duration of impacts while others reported impact durations of $30 \mathrm{~ms}$ or less.

\subsubsection{Impact Forces}

The HIC severity index is not enough for the assessment of head safety, especially for what concerns any potential damage to the skull and brain injury [111]. Contact force is another indicator to predict the fracture tolerance of the human bone structure. There have been many studies conducted on the heads of cadavers to measure the fracture forces of the skull. The experiments conducted were either by dropping the heads from different heights or impacting the head with an impactor at various velocities. A summary of the studies conducted on facial fracture (i.e. maxilla, zygoma, frontal bone, nasal bone, and mandible) revealed peak force tolerances anywhere in the range of 610-9,880 N [9]. An injury risk function with comparable consistency to facial fracture data has been proposed based on Weibull distribution [9,27]. The aim is to identify forces at which facial fracture starts for an impactor that has an area of $13.8 \mathrm{~cm}^{2}$. The function is defined as:

$P_{\text {fracture }}(F)=1-\exp \left[-\left(\frac{F}{B}\right)^{\alpha}\right]$

where $\alpha=2.27$ is the Weibull shape parameter, and $B=$ $887.7 \mathrm{~N}$ is the Weibull scale parameter, and $F$ is the impact force. According to this function, a force of $755 \mathrm{~N}$ would have $50 \%$ chance of fracture (Fig. 6).

\subsubsection{Tissue Injuries}

Tissue injuries resulting from impacts with objects could take on different forms, such as skin tears, lacerations and abrasions. The magnitude and the depth of the resultant injury depends on the geometry of impactors or penetrators and their dimensions [101]. Classification by depth is often used as an indicator for wounds and tissue injuries [106]. According to this classification, tissue injuries could either be superficial wounds, partial-thickness, full-thickness or sub- 


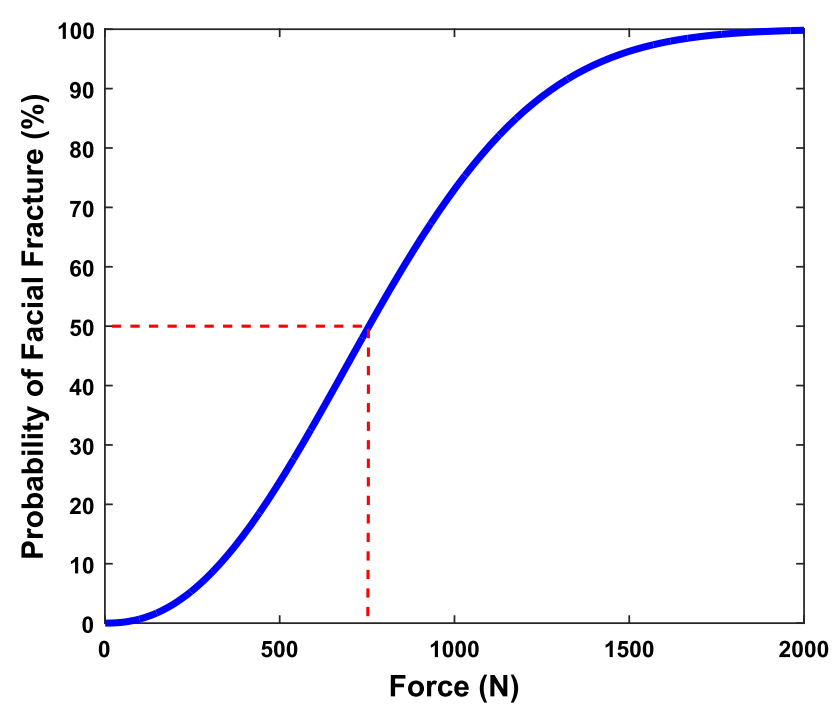

Fig. 6 Injury risk function for facial fractures (i.e. maxilla and zygoma) $[9,27]$. Dashed red line represents a facial fracture probability of $50 \%$ corresponding to a force value of $755 \mathrm{~N}$

cutaneous skin loss (Table 3). This classification will be used as a reference and indicator for the possible tissue injury in our study.

\section{Materials and Methods}

\subsection{Dummy Head Development}

A 3D printed head made of polylactide (PLA) was augmented with clay to reach a weight of $3.1 \mathrm{~kg}$ that is comparable to the weight of a scaled 50th percentile of 3-6 years old children's dummy heads [105]. A $2 \mathrm{~mm}$ layer of deformable soft material made of silicone (Ecoflex OO-30, Smooth-On, USA) was added to the dummy head to add more lifelike skin [18]. This silicone layer will be used in estimating potential tissue injuries due to its close Shore hardness value to that of the human skin [86]. The developed setup focuses on the dynamics of the head only because for short impact durations, the effects of the neck and body mass on the head are believed to be minimum [112].

A low-cost triple-axis accelerometer (ADXL 377, SparkFun Electronics, Colorado, USA) was placed at the center of the head to measure the linear acceleration of the head.

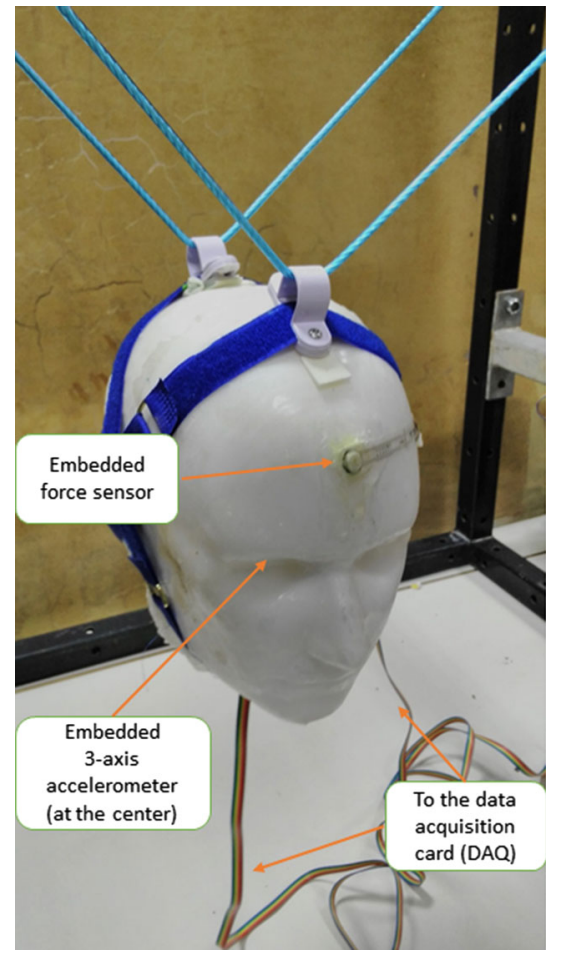

Fig. 7 The developed low-cost 3D printed head with the embedded sensors

A force-sensing resistor (FlexiForce Force Sensor, Tekscan Inc, USA) was placed at the center of the forehead to measure the impact forces (Fig. 7). The force sensor was calibrated according to the manufacturer's guide. A small puck (i.e. disk-like force concentrator) was placed at the center of the sensing area to ensure that most of the forces applied can be detected. In case the embedded sensor failed to properly register some of the impacts, a digital force gauge (FGE-100X, Shimpo Instruments, USA) was used in separate experiments to measure the impact forces by attaching it to the top of the head, thus increasing the total weight of the head to $3.5 \mathrm{~kg}$.

\subsection{Experimental Setup}

The experimental setup was based on a low-cost head model situated in a dedicated frame (Fig. 8). The dimensions of the frame were $\left(94.0 \times 94.0 \times 94.0 \mathrm{~cm}^{3}\right)$. Nylon coated

Table 3 Classification of tissue injury based on depth [106]

\begin{tabular}{llr}
\hline Classification & Affected skin layer & Depth \\
\hline Superficial & Only the epidermis & $<1 \mathrm{~mm}$ \\
Partial-thickness & The epidermis and into the dermis & $1-4 \mathrm{~mm}$ \\
Full-thickness & Through the epidermis and the dermis into the subcutaneous tissue & $>4 \mathrm{~mm}$ \\
Subcutaneous & Extends into and beyond the subcutaneous tissue & $>4 \mathrm{~mm}$ \\
\hline
\end{tabular}




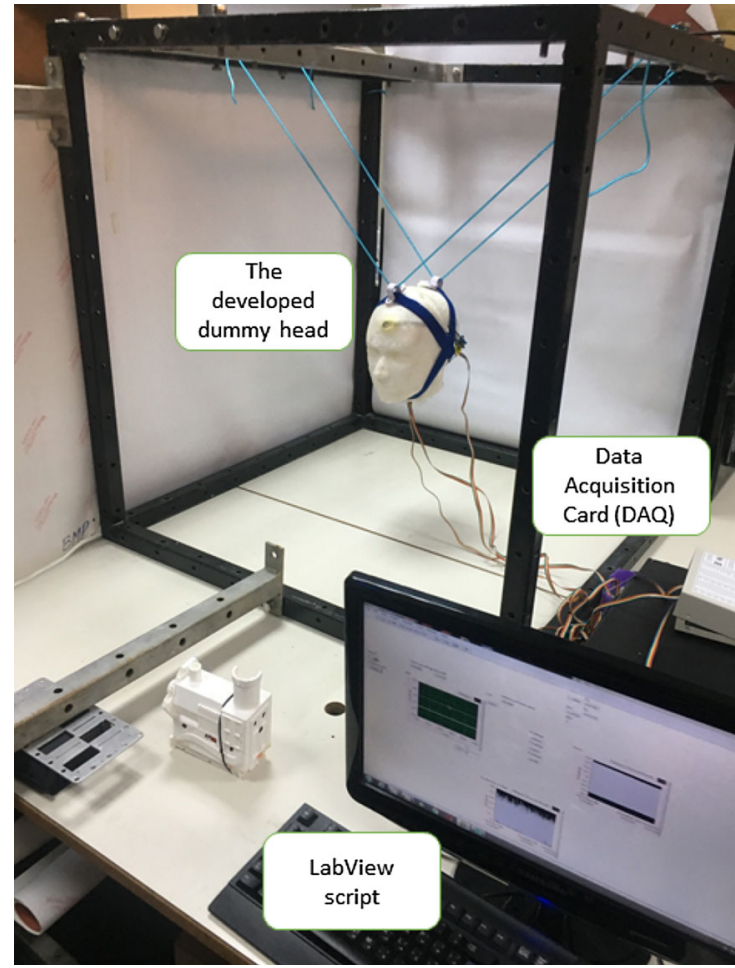

Fig. 8 The experimental setup used in this study

wire ropes were used to position the head at the center of the frame. Both sensors (i.e. accelerometer and force) were interfaced to a computer through a data acquisition card (PCI6031E, National Instrument, USA). The sampling rate was $20 \mathrm{kHz}$ and the signals were filtered according to the Channel Frequency Class 60 [104].

\subsection{Impactor}

To represent a small social robot, a 3D model with minimum features was designed and then fabricated using a 3D printer (Replicator 5th Generation, MakerBot Industries, USA; Fig. 9). The dimensions of the impactor are around $18.0 \times 8.0 \times 17.0 \mathrm{~cm}^{3}$ and weighs around $0.55 \mathrm{~kg}$. The surface roughness of the printed robot model was limited to the resolution of the $3 \mathrm{D}$ printer.

While there are many large social robots, the smaller ones are more affordable and are more suited for typical home users. The advancement in technology is allowing smaller robots to be more compact and intelligent. Hence, the size and mass of the proposed dummy robot falls according to such projections. Furthermore, the proposed parameters are within the potential range for throwing objects by the target users.
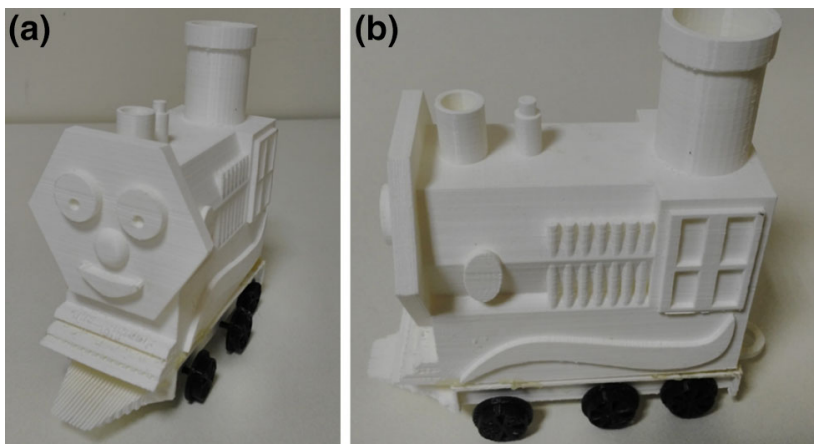

Fig. 9 The impactor representing a small social robot that has been used in the experiments. a Perspective view. b Side view

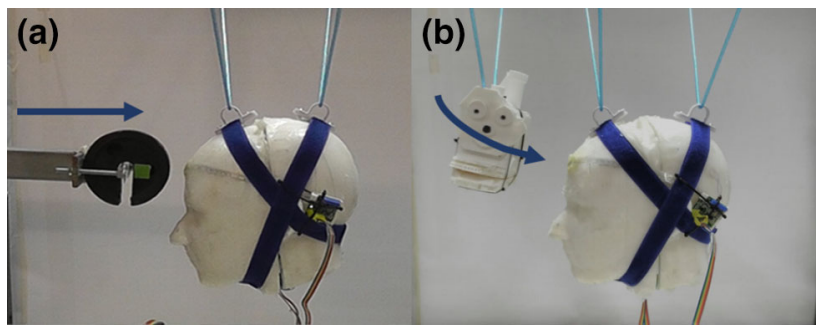

Fig. 10 Experiments that were conducted in this study. a Validation experiment with the $2 \mathrm{~kg}$ impactor. b Harm quantification experiment with the dummy robot

\subsection{Procedures}

\subsubsection{Setup Validation}

To verify the reliability of the developed setup in reporting the comparable HIC values, six impact tests at different velocities were conducted. The impactor used was a $2 \mathrm{~kg}$ mass attached to a beam (Fig. 10a). The beam was attached to the main frame of the setup and allowed for free motion that enabled it to hit the frontal side of the head at various velocities (see supplementary material). All impact tests were recorded and the corresponding HIC, 3 ms criterion, peak linear acceleration, and impact velocities were calculated.

\subsubsection{Harm Quantification}

Two different experiments of 15 trials each were conducted. Experiment 1 was in a more controlled condition as the dummy robot was tied with a rope to the frame to freely allow it to swing (Fig. 10b). Experiment 2 was in a more comparable condition to the realistic scenario. That involved the throwing of the dummy robot at various velocities from a distance of $1 \mathrm{~m}$ away from the head model. The velocities used were in the range of $2.5-8 \mathrm{~m} / \mathrm{s}$, which was within the range of a previously reported throwing speeds of tennis balls performed by children of different ages (i.e. 3-9 years) [96] We believe that this range is reasonable and comparable to 


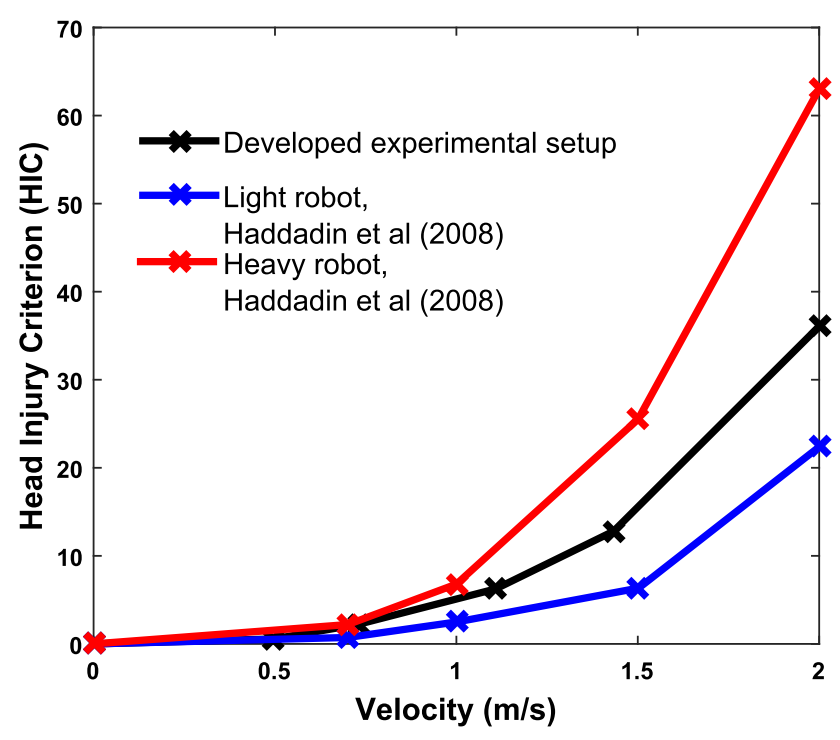

Fig. 11 Head injury criterion (HIC) values generated by the developed experimental setup due to different impact velocities with a $2 \mathrm{~kg}$ impactor. The results were compared with similar impacts conducted by different industrial robots

the throwing velocities that might be exerted by children on the spectrum.

All experiments were recorded using a video camera (FDR-X1000V, Sony, Japan) in slow-motion mode (240 fps, 720 pixels). All videos were analyzed using the open-source video analysis software Tracker (v4.10.0, Douglas Brown, Open Source Physics). A LabView (v2014, National Instrument, USA) script was used to obtain the raw data from the data acquisition card, processes it and then stores it in a worksheet file. The data were post-processed by a Matlab (v2015, MathWorks, Massachusetts, USA) script that generates the HIC, $3 \mathrm{~ms}$ criterion, and peak linear acceleration values.

\section{Results}

\subsection{Setup Validation}

To validate the head model setup, results were compared to previous studies of a similar nature $[44,45]$, where a low-cost dummy head was developed and an impactor of a mass of $1 \mathrm{~kg}$ was used for validation. The impact tests were conducted using robotic arms of different masses moving at different velocities and their results were then compared to that obtained with anthropomorphic test dummies (ATD). Their setup was able to reproduce a comparable numerical HIC values.

The generated HIC values from the validation impact tests in our study were comparable to Haddadin et al's previous studies (Fig. 11). For example, impact at a velocity of around $1 \mathrm{~m} / \mathrm{s}$ generated an HIC value in the range of $3-10$. The trend

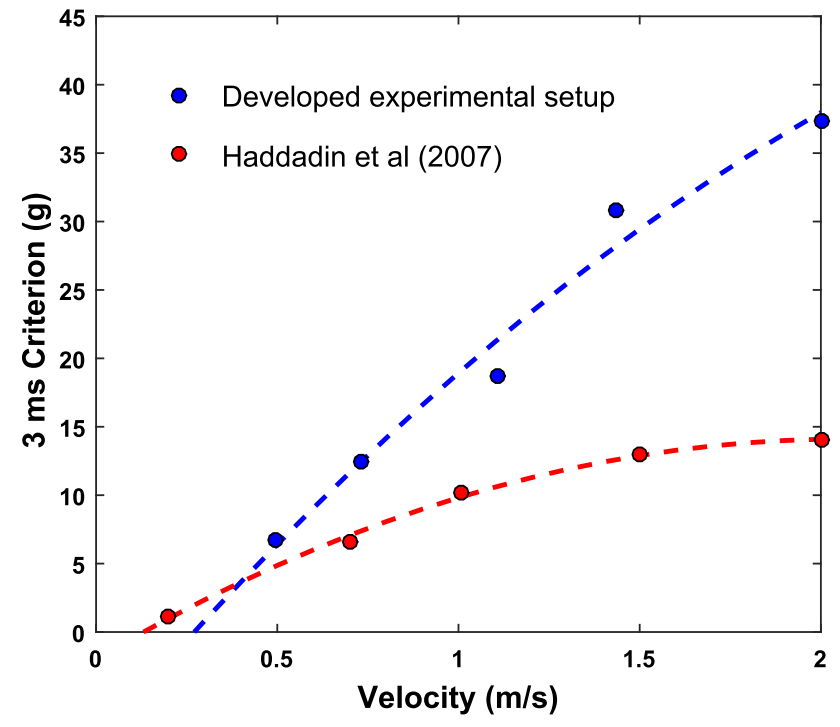

Fig. 12 The $3 \mathrm{~ms}$ criterion values generated due to different impact velocities with a $2 \mathrm{~kg}$ impactor. The results were compared with similar impacts conducted by an industrial robot

is also similar as the values of HIC obtained have increased proportionally with the applied impact velocities. As for the $3 \mathrm{~ms}$ criterion, the values at around $1 \mathrm{~m} / \mathrm{s}$ were in the range of 8-16 (Fig. 12). The differences in the values obtained can be attributed to the differences in the mass of the impactors used (i.e. $2 \mathrm{~kg}$ vs $1 \mathrm{~kg}$ ) and the mass of the developed dummy heads (i.e. $3.1 \mathrm{~kg}$ vs $4.5 \mathrm{~kg}$ ) $[56,73]$.

\subsection{Harm Quantification Measures}

\subsubsection{Head Injury Criterion (HIC)}

In Experiment 1, there is a more consistent trend that as the velocity of impact increases, the corresponding numerical HIC value increases (Fig. 13). The lowest recorded HIC value was 0.013 and it occurred at a velocity of $0.6 \mathrm{~m} / \mathrm{s}$ while the highest recorded HIC value was 8.568 corresponding to a velocity of $5 \mathrm{~m} / \mathrm{s}$.

In Experiment 2, the overall trend is less consistent at certain velocities as compared to Experiment 1, especially around $4 \mathrm{~m} / \mathrm{s}$. However, there is an increase in the recorded HIC values as the overall speed of throwing increases. The lowest HIC value obtained was 0.114 corresponding to a velocity of $3.9 \mathrm{~m} / \mathrm{s}$ while the highest recorded HIC value was 7.066 at a velocity of $7.48 \mathrm{~m} / \mathrm{s}$.

\subsubsection{The 3 ms Criterion}

In Experiment 1, the lowest recorded 3 ms value was 1.425 $\mathrm{g}$ and it occurred at a velocity of $0.6 \mathrm{~m} / \mathrm{s}$ while the highest recorded $3 \mathrm{~ms}$ value was $21.476 \mathrm{~g}$ corresponding to a velocity 


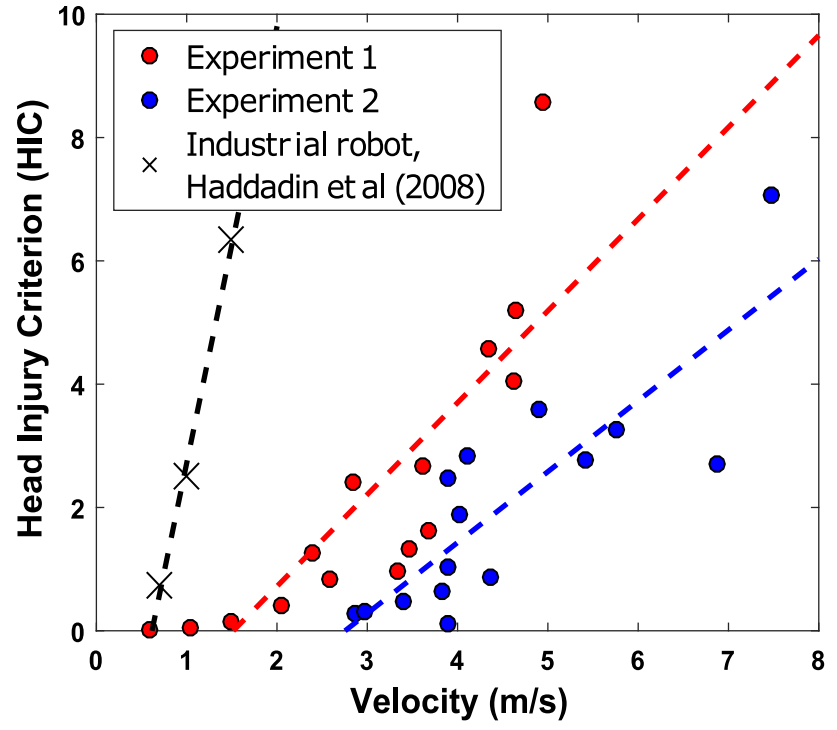

Fig. 13 The corresponding head injury criterion (HIC) values for impact experiments conducted in Experiment 1 and 2. Experiment 1 had the dummy robot attached to the experimental setup while Experiment 2 had the experimenter conduct the throwing of the dummy robot. The results were compared with the HIC values generated by an industrial robot

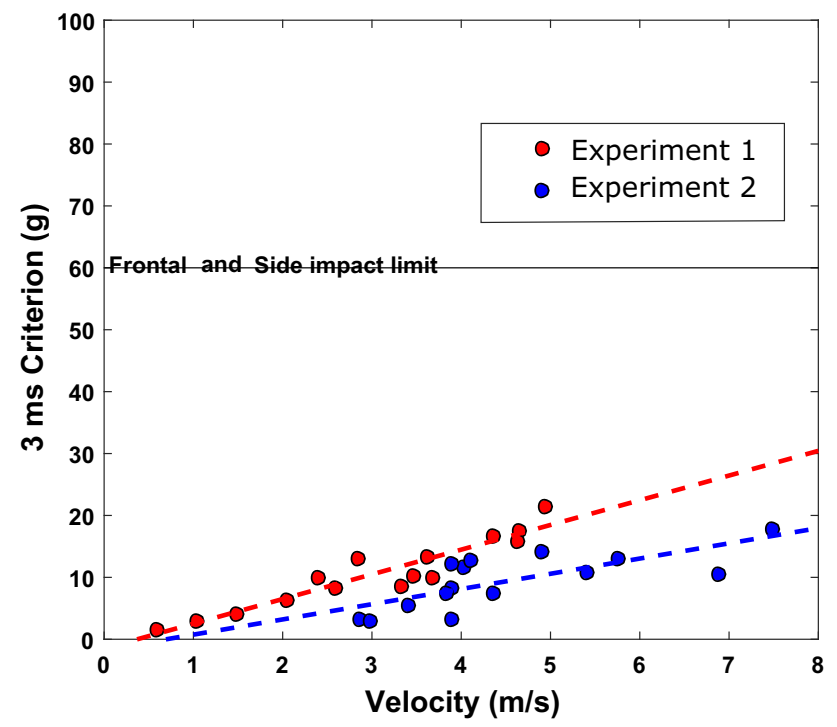

Fig. 14 The corresponding $3 \mathrm{~ms}$ criterion values for impact experiments conducted in Experiment 1 and 2. Experiment 1 had the dummy robot attached to the experimental setup while Experiment 2 had the experimenter conduct the throwing of the dummy robot. The results were compared to the $3 \mathrm{~ms}$ criterion thresholds for a child occupant [33]

of $5 \mathrm{~m} / \mathrm{s}$ (Fig. 14). The trend of the $3 \mathrm{~ms}$ values are linearly increasing with the applied velocities.

In Experiment 2, the lowest $3 \mathrm{~ms}$ value obtained was 2.96 g corresponding to a velocity of $2.97 \mathrm{~m} / \mathrm{s}$ while the highest recorded $3 \mathrm{~ms}$ value was $18 \mathrm{~g}$ at a velocity of $7.48 \mathrm{~m} / \mathrm{s}$ (Fig. 14). The trend is less consistent as compared to Experiment 1 as evident around $4 \mathrm{~m} / \mathrm{s}$.

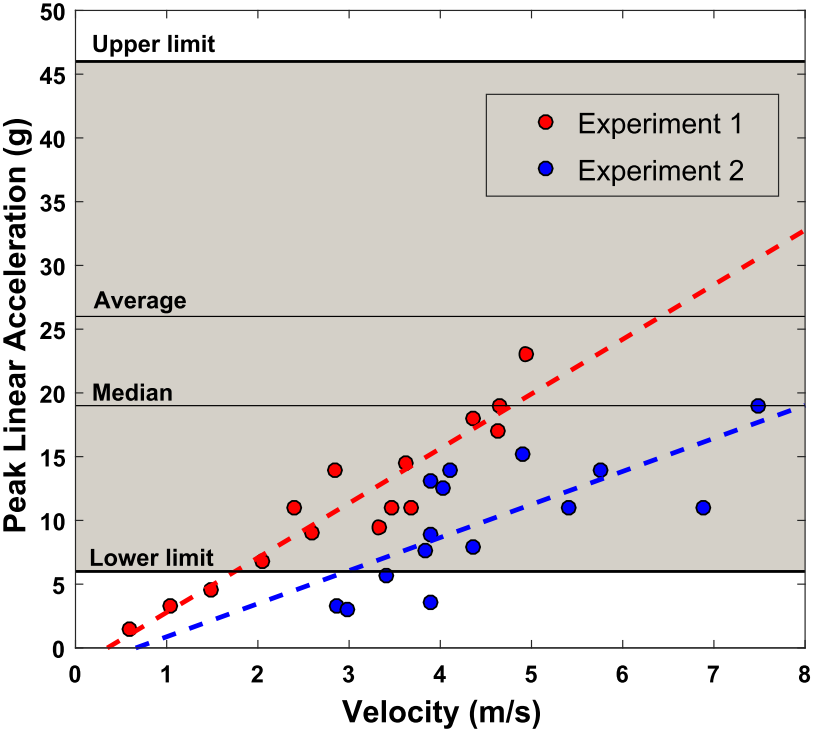

Fig. 15 The corresponding peak linear acceleration values for impact experiments conducted in Experiment 1 and 2. Experiment 1 had the dummy robot attached to the experimental setup while Experiment 2 had the experimenter conduct the throwing of the dummy robot. The highlighted area represents the range of peak linear accelerations that is associated with the occurrence of subconcussive events [93]

\subsubsection{Peak Linear Acceleration}

In Experiment 1, the lowest recorded peak linear acceleration value was $1.5 \mathrm{~g}$ and it occurred at a velocity of $0.6 \mathrm{~m} / \mathrm{s}$ while the highest recorded peak value was $23 \mathrm{~g}$ corresponding to a velocity of $5 \mathrm{~m} / \mathrm{s}$ (Fig. 15). The peak acceleration values are increasing linearly with the throwing velocity.

In Experiment 2, the lowest peak linear acceleration value obtained was $3 \mathrm{~g}$ corresponding to a velocity of $2.97 \mathrm{~m} / \mathrm{s}$ while the highest value was $19 \mathrm{~g}$ at a velocity of $7.48 \mathrm{~m} / \mathrm{s}$ (Fig. 15). the trend is less consistent as compared to Experiment 1 , especially around $4 \mathrm{~m} / \mathrm{s}$.

\subsubsection{Impact Forces}

The embedded force sensor approach has failed in registering some of the impacts or maximum values due to the lack of sufficient contact between the dummy robot and the effective area of the sensor. However, the maximum force recorded in all of the experiments was $28 \mathrm{~N}$ at a velocity of $5.75 \mathrm{~m} / \mathrm{s}$.

In order to get a better understanding of the potential impact forces involved, four separate experiments at different velocities were conducted using a stand-alone force gauge. These experiments were conducted similar to Experiment 1 (Fig. 10b). The lowest value was around $30.1 \mathrm{~N}$ corresponding to a velocity of $0.75 \mathrm{~m} / \mathrm{s}$ while the maximum value was $91.3 \mathrm{~N}$ at a velocity of $2.15 \mathrm{~m} / \mathrm{s}$. There is a trend and linear relationship between the applied velocities and the measured resultant peak force values (Fig. 16). 


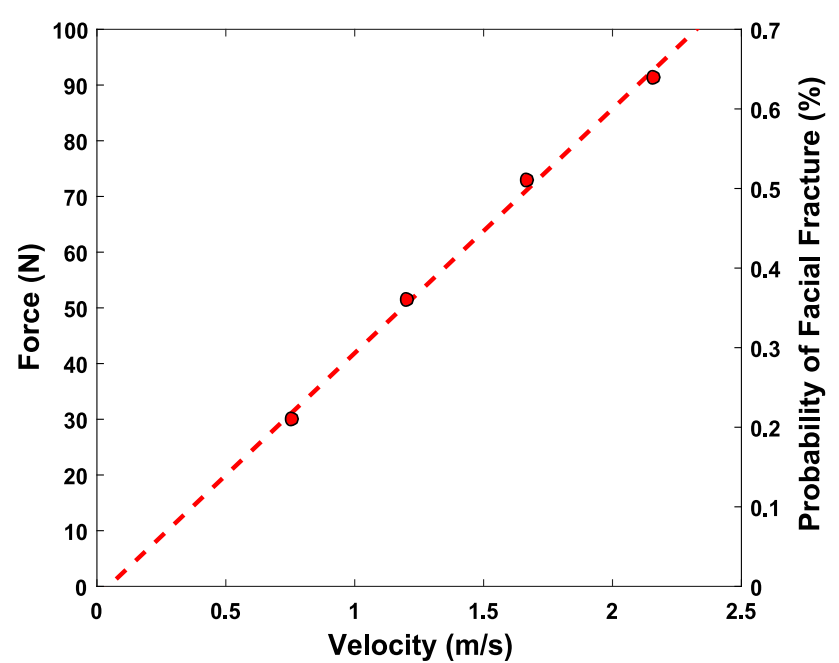

Fig. 16 The corresponding impact force values for impact experiments that were conducted using a stand-alone digital force gauge. The right axis represents their corresponding probabilities of causing facial fracture
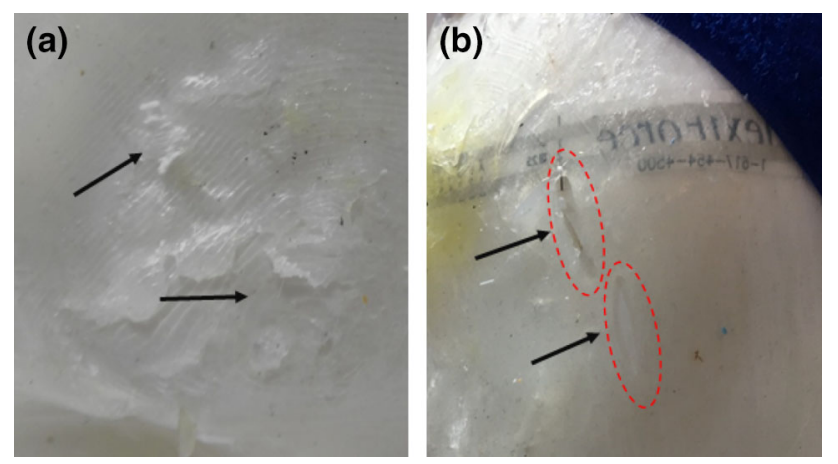

Fig. 17 The observed tissue damage to the artificial skin. a Abrasionslike skin damage of depth that is less than $1 \mathrm{~mm}$. b Laceration-like skin damage of depth that is equal or greater than $2 \mathrm{~mm}$

\subsubsection{Tissue Injuries}

The evaluation of tissue injuries was based on the visual inspection of the artificial skin. All observations were made after conducting Experiment 1 and Experiment 2. In terms of depth, the majority of the observed damage to the artificial skin were less than $1 \mathrm{~mm}$ (Fig. 17a). There were some instances where the depth of the observed damage was more than the thickness of the artificial skin (i.e. greater than 2 $\mathrm{mm}$ ), which pierced the dummy head (Fig. 17b).

\section{Discussion}

For the HIC values to be meaningful, they need to be translated to a corresponding metric for potential injury based on the AIS. From the reported equations in Sect. 3, the probabilities of injury due to all impact tests conducted in both

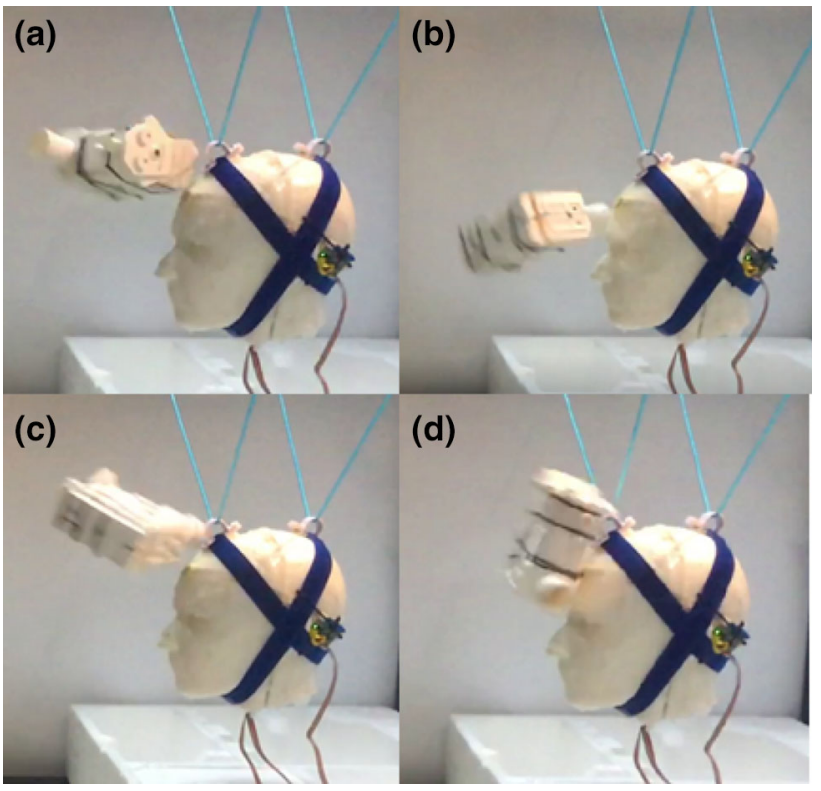

Fig. 18 Surface areas of the dummy robot that hit the head. a Frontal edge. b Chimney. c Back. d Side

Experiments 1 and 2 were negligible (i.e. close to 0\%). Even though all the estimated potential for injuries in our experiments were low, there is still a potential for serious harm based on the reported catastrophic injuries and fatalities that occurred due to impacts with lighter objects (e.g. baseball) among children [12,71]. While the HIC severity index is significant in giving an estimation of the potential for head injury, it is insufficient to estimate pain and assess tissue injuries.

As for the $3 \mathrm{~ms}$ criterion, the maximum values obtained for both sets indicate a low potential for harm. The highest value for Experiment 1 is around $36 \%$ of the $3 \mathrm{~ms}$ criterion impact limit (i.e. $60 \mathrm{~g}$ for frontal and side impacts). As for Experiment 2, the corresponding percentage for the highest $3 \mathrm{~ms}$ value is around $30 \%$ for the $3 \mathrm{~ms}$ criterion impact limit of $60 \mathrm{~g}$.

The values for the peak linear accelerations for both experiments were around $20 \mathrm{~g}$, which were far from most of the reported peak accelerations (e.g. 66-106 g) that are associated with concussive events [119]. However, most of the obtained peak acceleration values fall within the range (i.e. 6-46 g) that is associated with subconcussive events (Fig. 15). Furthermore, two peak linear acceleration values were at or above the reported median value of $19 \mathrm{~g}$ that has been associated with the occurrence of subconcussive impacts, where the occurrence of which has been linked to neurocognitive deficits [93]. More research needs to be done to understand the biomechanical variables and its relation to causing concussion or mild TBI among children.

For the HIC, $3 \mathrm{~ms}$ criterion, and peak linear acceleration results, there was a noticeable disparity in Experiment 2 at 


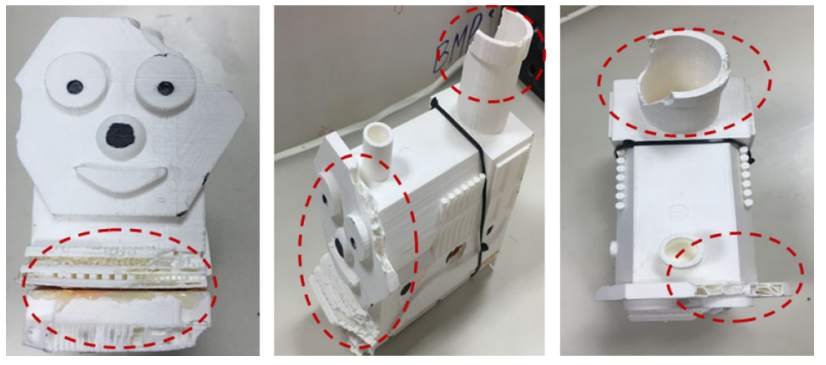

Fig. 19 The sustained damage on the small robot after the completion of the experiments

a velocity of around $4 \mathrm{~m} / \mathrm{s}$. For example, the range of HIC values was from 0.114 to 2.834 . This discrepancy can be attributed to the surface or area of the dummy robot that hit the head (e.g. chimney vs side) as observed from the analysis of the recorded videos (Fig. 18). This implies that at higher velocities, the harm level could even be larger depending on the contact area.

The peak force values for all the experiments were translated to percentages corresponding to the potential of causing fracture to the skull based on the previously stated relation (Fig. 6). All the recorded peak forces have a low potential to cause real harm to any of the facial bones. For example, a peak value of $91.3 \mathrm{~N}$ (i.e. the maximum value obtained) corresponds to around $0.6 \%$ chance of causing fracture to the bones of the face. However, assuming the linear relation holds true for higher velocities (Fig. 16), the chance for facial fracture increases to $20 \%$ at a hypothetical throwing velocity of $10 \mathrm{~m} / \mathrm{s}$ for the same robot.

The depth of the observed artificial skin damage correspond to the tissue injuries based on the classification listed in Table 3. Most of the damage caused by the impacts conducted in this study falls into the superficial category that affects the epidermis layer, and they were in the form of abrasions. There were few lacerations that are classified as partial-thickness skin loss that would require medical care. No instances of full-thickness (i.e. depth greater than $4 \mathrm{~mm}$ ) skin loss were observed.

The dummy robot sustained a considerable damage (Fig. 19). The damage was more apparent after performing Experiment 2 (i.e. mimicking real throwing scenario). Some of the lacerations on the artificial skin of the head could have resulted from the newly formed sharp edges on the robot due to the sustained damage from some of the initial impacts. This implies that any robotic design should remain robust and safe, especially after being subjected to similar impacts and conditions. Superficial injury as an indicator for potential harm could be better than some of the typical severity indices. A similar conclusion has been reached in studies investigating the potential harm in industrial robots $[43,44]$.
The investigations conducted in this study were limited to a potential scenario that may happen between a child and a social robot wherein a child throws a robot to the face of another person. Quantifying harm was limited to the head. Measurements of injury to the head was limited to the existing severity indices and to the available data from the literatures. Thus, some aspects could not be measured, such as pain levels. The tissue injury investigations were limited to the artificial skin. Thus, the actual depth of lacerations on in vivo tissues might differ. Finally, the study was limited to small form factor impactor representing a small social robot. Hence, the obtained results are only applicable to closely comparable robots in terms of mass, design, material, and size.

\section{Conclusion}

The motivation of this study was to investigate the potential for harm due to the interaction between social robots and children with ASD, especially during the manifestation of challenging behaviors. Throwing, kicking, hitting, and selfharming are some of the challenging behaviors that could inflict some harm to the children themselves and to those around them. Our investigation of harm due to the throwing of a small social robot revealed that it could potentially cause tissue injuries, subconcussive or concussive event in extreme cases.

Social robots have gained a lot of attention in healthcare generally, and specifically in therapy, due to the increased number of studies reporting the efficacy of using such technology. Among children with ASD, social robots have been reported to effectively help in the elicitation of some positive behaviors. This has been attributed to the fact that social robots are simpler and are less complicated than humans. The advancement in technology has enabled robots to be more autonomous, intelligent and has opened new possibilities for smaller social robotic forms exhibiting high interactivity. While larger social robots can be used in therapeutic settings, especially for training, the smaller form of social robots are more affordable and suitable in home usage for continuous monitoring. The introduction of a new tool, such as a social robot, that is meant to evoke behaviors could pose as a new source of harm to the children themselves or others.

Children on the spectrum lack the ability to properly communicate their needs $[64,103]$. Generalization of skills is usually done with other children. Hence, being subjected to pain due to impacts might affect any positive outcomes, and potentially cause more challenging behaviors. Any source of potential harm, pain or even annoyance must be kept to a minimum or eliminated altogether.

More research needs to be done on investigating the potential for harm due to the different robotic forms and to search 
for means to mitigate them through hardware and software approaches $[63,65]$. For small social robots, regulations from standards that are concerned with the safety of toys can readily be adopted. For example, ISO 8124-1:2014 is related to the mechanical and physical properties of the safety aspects of toys [61]. Another direction for safer social robots is the adoption of some of the techniques and advances in soft robotics [51], which could potentially allow the embedding of different biopolymer-based sensors [95]. New social robotic safety standards for special needs children, such as children with ASD, must be established to ensure their safety and to take their needs into consideration.

Acknowledgements The work is supported by a research grant from Qatar University under the grant No. QUST-1-CENG-2018-7. The statements made herein are solely the responsibility of the authors.

\section{Compliance with Ethical Standards}

Conflicts of interest The authors declare that they have no conflict of interest.

Open Access This article is distributed under the terms of the Creative Commons Attribution 4.0 International License (http://creativecomm ons.org/licenses/by/4.0/), which permits unrestricted use, distribution, and reproduction in any medium, provided you give appropriate credit to the original author(s) and the source, provide a link to the Creative Commons license, and indicate if changes were made.

\section{References}

1. Alhaddad AY, Javed H, Connor O, Banire B, Al Thani D, Cabibihan JJ (2019) Robotic trains as an educational and therapeutic tool for Autism Spectrum Disorder Intervention. In: Lepuschitz W, Merdan M, Koppensteiner G, Balogh R, Obdržálek D (eds) Robotics in Education. RiE 2018. Advances in intelligent systems and computing, vol 829. Springer, Cham

2. Anderson V, Moore C (1995) Age at injury as a predictor of outcome following pediatric head injury: A longitudinal perspective. Child Neuropsychol 1(3):187-202

3. Anderson VA, Catroppa C, Dudgeon P, Morse SA, Haritou F, Rosenfeld JV (2006) Understanding predictors of functional recovery and outcome 30 months following early childhood head injury. Neuropsychology 20(1):42

4. Ashburner J, Ziviani J, Rodger S (2010) Surviving in the mainstream: Capacity of children with autism spectrum disorders to perform academically and regulate their emotions and behavior at school. Res Autism Spectr Disord 4(1):18-27

5. Association AP et al (2013) Diagnostic and statistical manual of mental disorders (DSM - 5®). American Psychiatric Pub

6. Auger R (2013) Autism spectrum disorders: A research review for school counselors. Prof Sch Couns 16(4):256-268

7. Baghdadli A, Pascal C, Grisi S, Aussilloux C (2003) Risk factors for self-injurious behaviours among 222 young children with autistic disorders. J Intellect Disabil Res 47(8):622-627

8. Bakhos LL, Lockhart GR, Myers R, Linakis JG (2010) Emergency department visits for concussion in young child athletes. Pediatrics 126(3):e550-e556
9. Bass CR, Yoganandan N (2015) Skull and facial bone injury biomechanics. In: Yoganandan N, Nahum AM, Melvin JW (eds) Accidental injury, pp 203-220. Springer, Berlin

10. Begum M, Serna RW, Yanco HA (2016) Are robots ready to deliver autism interventions? A comprehensive review. Int J Soc Robot 8(2):157-181

11. Boccanfuso L, Barney E, Foster C, Ahn YA, Chawarska K, Scassellati B, Shic F (2016) Emotional robot to examine differences in play patterns and affective response of children with and without ASD. In: The eleventh ACM/IEEE International Conference on Human Robot Interaction, pp 19-26. IEEE Press

12. Boden BP, Tacchetti R, Mueller FO (2004) Catastrophic injuries in high school and college baseball players. Am J Sports Med 32(5):1189-1196

13. Bodfish JW, Symons FJ, Parker DE, Lewis MH (2000) Varieties of repetitive behavior in autism: Comparisons to mental retardation. J Autism Dev Disord 30(3):237-243

14. Breazeal C, Dautenhahn K, Kanda T (2016) Social robotics. In: Siciliano B, Khatib O (eds) Springer handbook of robotics, pp 1935-1972. Springer, Berlin

15. Cabibihan JJ, Javed H, Aldosari M, Frazier TW, Elbashir H (2016) Sensing technologies for autism spectrum disorder screening and intervention. Sensors 17(1):46

16. Cabibihan JJ, Javed H, Ang M Jr, Aljunied SM (2013) Why robots? A survey on the roles and benefits of social robots in the therapy of children with autism. Int J Soc Robot 5(4):593-618

17. Cabibihan JJ, Javed H, Sadasivuni, KK, Al Haddad AY (2018) Smart robotic therapeutic learning toy. WIPO Patent WO2018033857. World Intellectual Property Organization

18. Cabibihan JJ, Joshi D, Srinivasa YM, Chan MA, Muruganantham A (2015) Illusory sense of human touch from a warm and soft artificial hand. IEEE Trans Neural Syst Rehabil Eng 23(3):517527

19. Cabibihan JJ, So WC, Nazar M, Ge SS (2009) Pointing gestures for a robot mediated communication interface. In: International Conference on Intelligent Robotics and Applications, pp 67-77. Springer, Berlin, Heidelberg

20. Cabibihan JJ, So WC, Pramanik S (2012) Human-recognizable robotic gestures. IEEE Trans Auton Ment Dev 4(4):305-314

21. Cabibihan JJ, So WC, Saj S, Zhang Z (2012) Telerobotic pointing gestures shape human spatial cognition. Int J Soc Robot 4(3):263272

22. Casey D, Felzmann H, Pegman G, Kouroupetroglou C, Murphy K, Koumpis A, Whelan S (2016) What people with dementia want: Designing Mario an acceptable robot companion. In: International conference on computers helping people with special needs, pp 318-325. Springer

23. Cashin A, Barker P (2009) The triad of impairment in autism revisited. J Child Adolesc Psychiatr Nurs 22(4):189-193

24. Chaudron S, Di Gioia R, Gemo M, Holloway D, Marsh J, Mascheroni G, Peter J, Yamada-Rice D (2017) Kaleidoscope on the internet of toys-safety, security, privacy and societal insights. Publications Office of the European Union. http://publications. europa.eu/en/publication-detail/-/publication/a1642559-ec3711e6-ad7c-01aa75ed71a1/language-en

25. Cordero CA, Carbone G, Ceccarelli M, Echávarri J, Muñoz JL (2014) Experimental tests in human-robot collision evaluation and characterization of a new safety index for robot operation. Mech Mach Theory 80:184-199

26. Cotugno AJ (2009) Social competence and social skills training and intervention for children with autism spectrum disorders. J Autism Dev Disord 39(9):1268-1277

27. Davis MB (2004) Facial fracture and eye injury tolerance from night vision goggle loading. Ph.D. thesis, University of Virginia

28. Desideri L, Negrini M, Malavasi M, Tanzini D, Rouame A, Cutrone MC, Bonifacci P, Hoogerwerf EJ (2018) Using a 
humanoid robot as a complement to interventions for children with autism spectrum disorder: A pilot study. Adv Neurodev Disord 2:273-285

29. Diep L, Cabibihan JJ, Wolbring G (2015) Social robots: Views of special education teachers. In: Proceedings of the 3rd 2015 Workshop on ICTs for Improving Patients Rehabilitation Research Techniques, pp 160-163. ACM

30. Ennis-Cole DL (ed) (2015) Strategies for supporting students with ASD. In: Technology for learners with autism spectrum disorders, pp 15-27. Springer

31. Ennis-Cole DL (2015) Technology for learners with autism spectrum disorders. Springer, Berlin

32. Estes A, Munson J, Dawson G, Koehler E, Zhou XH, Abbott R (2009) Parenting stress and psychological functioning among mothers of preschool children with autism and developmental delay. Autism 13(4):375-387

33. European New Car Assessment Programme (Euro NCAP) (2017) Assessment protocol-child occupant protection. http://cdn. euroncap.com/media/32281/euro-ncap-assessment-protocolcop-v721.pdf

34. Fife GP, O'sullivan DM, Pieter W, Cook DP, Kaminski TW (2012) Effects of olympic-style taekwondo kicks on an instrumented head-form and resultant injury measures. Br J Sports Med 47:1161-1165

35. Fodstad JC, Rojahn J, Matson JL (2012) The emergence of challenging behaviors in at-risk toddlers with and without autism spectrum disorder: A cross-sectional study. J Dev Phys Disabilities 24(3):217-234

36. Fong T, Nourbakhsh I, Dautenhahn K (2003) A survey of socially interactive robots. Robot Auton Syst 42(3-4):143-166

37. Ge SS, Cabibihan JJ, Zhang Z, Li Y, Meng C, He H, Safizadeh M, Li Y, Yang J (2011) Design and development of Nancy, a social robot. In: 2011 8th International Conference on Ubiquitous Robots and Ambient Intelligence (URAI), pp 568-573. IEEE

38. Giuliani M, Lenz C, Müller T, Rickert M, Knoll A (2010) Design principles for safety in human-robot interaction. Int J Soc Robot 2(3):253-274

39. Green H, McGinnity Á, Meltzer H, Ford T, Goodman R (2005) Mental health of children and young people in Great Britain, 2004. Palgrave. http://no-pa.uk/wp-content/uploads/2015/02/Mentalhealth-ofchildren.pdf

40. Greenspan L, McLellan BA, Greig H (1985) Abbreviated injury scale and injury severity score: A scoring chart. J Trauma Acute Care Surg 25(1):60-64

41. Greenwald RM, Gwin JT, Chu JJ, Crisco JJ (2008) Head impact severity measures for evaluating mild traumatic brain injury risk exposure. Neurosurgery 62(4):789-798

42. Gurney JG, McPheeters ML, Davis MM (2006) Parental report of health conditions and health care use among children with and without autism: National survey of children's health. Arch Pediatr Adolesc Med 160(8):825-830

43. Haddadin S, Albu-Schaffer A, Haddadin F, Rosmann J, Hirzinger G (2011) Study on soft-tissue injury in robotics. IEEE Robot Autom Mag 18(4):20-34

44. Haddadin S, Albu-Schäffer A, Hirzinger G (2007) Safety evaluation of physical human-robot interaction via crash-testing. In: Robotics: Science and systems 2007, vol 3, pp 217-224. http:// www.roboticsproceedings.org/rss03/p28.pdf

45. Haddadin S, Albu-Schaffer A, Hirzinger G (2008) The role of the robot mass and velocity in physical human-robot interactionPart I: Non-constrained blunt impacts. In: IEEE International Conference on Robotics and Automation, 2008. ICRA 2008. pp 1331-1338. IEEE

46. Haddadin S, Albu-Schäffer A, Hirzinger G (2009) Requirements for safe robots: Measurements, analysis and new insights. Int $\mathrm{J}$ Robot Res 28(11-12):1507-1527
47. Ham J, Cuijpers RH, Cabibihan JJ (2015) Combining robotic persuasive strategies: The persuasive power of a storytelling robot that uses gazing and gestures. Int J Soc Robot 7(4):479-487

48. Hart M (2005) Autism/excel study. In: Proceedings of the 7th International ACM SIGACCESS Conference on Computers and Accessibility, pp 136-141. ACM

49. Hegel F, Muhl C, Wrede B, Hielscher-Fastabend M, Sagerer G (2009) Understanding social robots. In: Second International Conferences on Advances in Computer-Human Interactions, 2009. ACHI'09. pp 169-174. IEEE

50. Herrmann G, Melhuish C (2010) Towards safety in human robot interaction. Int J Soc Robot 2(3):217-219

51. Hoa TD, Cabibihan JJ (2012) Cute and soft: Baby steps in designing robots for children with autism. In: Proceedings of the workshop at SIGGRAPH Asia, pp 77-79. ACM

52. Huijnen C, Lexis M, de Witte L (2017) Robots as new tools in therapy and education for children with autism. Int J Neurorehabilit 4(278):0281-2376

53. Huijnen CA, Lexis MA, Jansens R, de Witte LP (2017) How to implement robots in interventions for children with autism? A co-creation study involving people with autism, parents and professionals. J Autism Dev Disord 47(10):3079-3096

54. Huijnen CA, Lexis MA, de Witte LP (2016) Matching robot Kaspar to Autism Spectrum Disorder (ASD) therapy and educational goals. Int J Soc Robot 8(4):445-455

55. Hutchins TL, Prelock PA (2014) Using communication to reduce challenging behaviors in individuals with autism spectrum disorders and intellectual disability. Child Adolesc Psychiatr Clin 23(1):41-55

56. Hutchinson TP (2014) Peak acceleration during impact with helmet materials: Effects of impactor mass and speed. Eur J Sport Sci 14(sup1):S377-S382

57. International Federation of Robotics: Press Releases (2016). https://ifr.org/downloads/press/02_2016/2016-DEC_20_IFR_ press_release_service_robots_2019_FINAL_QS.pdf

58. International Organization for Standardization (2011) ISO 10218-1: 2011: Robots and robotic devices-safety requirements for industrial robots-Part 1: Robots. International Organization for Standardization, Geneva

59. International Organization for Standardization (2011) ISO 10218-2: 2011: Robots and robotic devices-safety requirements for industrial robots-Part 2: Robot systems and integration. International Organization for Standardization, Geneva

60. International Organization for Standardization (2014) ISO 13482: 2014: Robotic devices-safety requirements-Nonmedical personal care robot. International Organization for Standardization, Geneva

61. International Organization for Standardization (2014) ISO 8124 1: 2014: Safety of toys - Part 1: Safety aspects related to mechanical and physical properties. International Organization for Standardization, Geneva

62. International Organization for Standardization (2016) ISO/ts 15066:2016: Robots and robotic devices-Collaborative robots. Geneva, Switzerland: International Organization for Standardization

63. Javed H, Cabibihan JJ, Al-Attiyah AA (2015) Autism in the Gulf States: Why social robotics is the way forward. In: ICTA, pp 1-3

64. Javed H, Cabibihan JJ, Aldosari M, Al-Attiyah A (2016) Culture as a driver for the design of social robots for autism spectrum disorder interventions in the Middle East. In: International Conference on Social Robotics, pp 591-599. Springer, Cham

65. Javed H, Connor OB, Cabibihan JJ (2015) Thomas and friends: Implications for the design of social robots and their role as social story telling agents for children with autism. In: 2015 IEEE international Conference on Robotics and Biomimetics (ROBIO), pp 1145-1150. IEEE 
66. Johnson NL, Lashley J, Stonek AV, Bonjour A (2012) Children with developmental disabilities at a pediatric hospital: Staff education to prevent and manage challenging behaviors. J Pediatr Nurs 27(6):742-749

67. Kanne SM, Mazurek MO (2011) Aggression in children and adolescents with ASD: Prevalence and risk factors. J Autism Dev Disord 41(7):926-937

68. Kozima H, Michalowski MP, Nakagawa C (2009) Keepon. Int J Soc Robot 1(1):3-18

69. Kozlowski AM, Matson JL (2012) An examination of challenging behaviors in autistic disorder versus pervasive developmental disorder not otherwise specified: Significant differences and gender effects. Res Autism Spectr Disord 6(1):319-325

70. Kuppa S (2004) Injury criteria for side impact dummies. Washington, DC: National Transportation Biomechanics Research Center, vol 67 National Highway Saftey Administration, US DOT

71. Kyle S, Adler P, Monticone R (1996) Reducing youth baseball injuries with protective equipment. Consum Product Saf Rev 1(1): $1-4$

72. Machalicek W, OReilly MF, Beretvas N, Sigafoos J, Lancioni GE (2007) A review of interventions to reduce challenging behavior in school settings for students with autism spectrum disorders. Res Autism Spectr Disord 1(3):229-246

73. Martin R, Liptai L, Yerby S, Williams K (1994) The relationship between mass and acceleration for impacts on padded surfaces. $\mathrm{J}$ Biomech 27(3):361-364

74. Mascheroni G, Holloway D (eds) (2017) The internet of toys: A report on media and social discourses around young children and iotoys. DigiLitEY. http://digilitey.eu/wp-content/uploads/2017/ 01/IoToys-June-2017-reduced.pdf

75. Matson JL, Gonzalez ML, Rivet TT (2008) Reliability of the autism spectrum disorder-behavior problems for children (ASDBPC). Res Autism Spectr Disord 2(4):696-706

76. Matson JL, Shoemaker M (2009) Intellectual disability and its relationship to autism spectrum disorders. Res Dev Disabil 30(6):1107-1114

77. Mazefsky CA, Herrington J, Siegel M, Scarpa A, Maddox BB, Scahill L, White SW (2013) The role of emotion regulation in autism spectrum disorder. J Am Acad Child Adolesc Psychiatry 52(7):679-688

78. McIntosh AS, Janda D (2003) Evaluation of cricket helmet performance and comparison with baseball and ice hockey helmets. Br J Sports Med 37(4):325-330

79. Michaud F, Caron S (2002) Roball, the rolling robot. Autonom Robots 12(2):211-222

80. Mihalik JP, Blackburn JT, Greenwald RM, Cantu RC, Marshall SW, Guskiewicz KM (2010) Collision type and player anticipation affect head impact severity among youth ice hockey players. Pediatrics 125(6):e1394-e1401

81. Murphy O, Healy O, Leader G (2009) Risk factors for challenging behaviors among 157 children with autism spectrum disorder in ireland. Res Autism Spectr Disord 3(2):474-482

82. Myers SM, Johnson CP et al (2007) Management of children with autism spectrum disorders. Pediatrics 120(5):1162-1182

83. National Center for Injury Prevention and Control (2003) Report to congress on mild traumatic brain injury in the United States: Steps to prevent a serious public health problem. Centers for Disease Control and Prevention, Atlanta, GA. https://www.cdc.gov/ traumaticbraininjury/pdf/mtbireport-a.pdf

84. Oberer S, Schraft RD (2007) Robot-dummy crash tests for robot safety assessment. In: 2007 IEEE International Conference on Robotics and Automation, pp 2934-2939. IEEE

85. O'sullivan DM, Fife GP, Pieter W, Shin I (2013) Safety performance evaluation of taekwondo headgear. Br J Sports Med 47(7):447-451
86. Panduri S, Dini V, Romanelli M (2017) The durometer measurement of the skin: Hardware and measuring principles. In: Humbert P, Fanian F, Maibach H, Agache P (eds) Agache's measuring the skin. Springer, Cham

87. Parsons S, Mitchell P, Leonard A (2004) The use and understanding of virtual environments by adolescents with autistic spectrum disorders. J Autism Dev Disord 34(4):449-466

88. Plant KM, Sanders MR (2007) Reducing problem behavior during care-giving in families of preschool-aged children with developmental disabilities. Res Dev Disabil 28(4):362-385

89. Rivara FP, Koepsell TD, Wang J, Temkin N, Dorsch A, Vavilala MS, Durbin D, Jaffe KM (2012) Incidence of disability among children 12 months after traumatic brain injury. Am J Public Health 102(11):2074-2079

90. Robins B, Dautenhahn K, Dickerson P (2009) From isolation to communication: A case study evaluation of robot assisted play for children with autism with a minimally expressive humanoid robot. In: Second International Conferences on Advances in ComputerHuman Interactions, 2009. ACHI'09. pp 205-211. IEEE

91. Robins B, Otero N, Ferrari E, Dautenhahn K (2007) Eliciting requirements for a robotic toy for children with autism-results from user panels. In: The 16th IEEE International Symposium on Robot and Human Interactive Communication, 2007. RO-MAN 2007, pp 101-106. IEEE

92. Rogers SJ (1996) Brief report: Early intervention in autism. J Autism Dev Disord 26(2):243-246

93. Rowson S, Duma SM (2011) Development of the star evaluation system for football helmets: Integrating player head impact exposure and risk of concussion. Ann Biomed Eng 39(8):2130-2140

94. Rowson S, Duma SM (2013) Brain injury prediction: Assessing the combined probability of concussion using linear and rotational head acceleration. Ann Biomed Eng 41(5):873-882

95. Sadasivuni KK, Al Haddad AY, Javed H, Yoon WJ, Cabibihan JJ (2017) Strain, pressure, temperature, proximity, and tactile sensors from biopolymer composites. In: Biopolymer composites in electronics, pp 437-457. Elsevier

96. Sakurai S, Miyashita M (1983) Developmental aspects of overarm throwing related to age and sex. Human Mov Sci 2(1):67-76

97. Scarpinato N, Bradley J, Kurbjun K, Bateman X, Holtzer B, Ely B (2010) Caring for the child with an autism spectrum disorder in the acute care setting. J Spec Pediatr Nurs 15(3):244-254

98. Scassellati B, Admoni H, Mataric M (2012) Robots for use in autism research. Ann Rev Biomed Eng 14:275-294

99. Schmitt KU, Niederer PF, Muser MH, Walz F (2009) Trauma biomechanics: Accidental injury in traffic and sports. Springer, Berlin

100. Share P, Pender J (2018) Preparing for a robot future? Social professions, social robotics and the challenges ahead. Irish J Appl Soc Stud 18(1):4

101. Shergold OA, Fleck NA (2005) Experimental investigation into the deep penetration of soft solids by sharp and blunt punches, with application to the piercing of skin. J Biomech Eng 127(5):838848

102. Siciliano B, Khatib O (2016) Springer handbook of robotics. Springer, Berlin

103. So WC, Wong MY, Cabibihan JJ, Lam CY, Chan RY, Qian HH (2016) Using robot animation to promote gestural skills in children with autism spectrum disorders. J Comput Assist Learn 32(6):632-646

104. Society of Automotive Engineers. (1995). Instrumentation for impact test-Part 1-Electronic instrumentation. SAE, 211

105. Solutions, Humanetics Innovative: Hybrid III 3 year old child. Child dummies. http://www.humaneticsatd.com/crashtest-dummies/children/hiii-3yo (2017). Date last accessed 1 Jan 2018 
106. Sussman C, Bates-Jensen BM (2007) Wound care: A collaborative practice manual. Lippincott Williams \& Wilkins, Philadelphia

107. Taheri A, Meghdari A, Alemi M, Pouretemad H (2017) Humanrobot interaction in autism treatment: A case study on three pairs of autistic children as twins, siblings, and classmates. Int J Soc Robot 10(1):93-113

108. Taylor CA (2017) Traumatic brain injury-related emergency department visits, hospitalizations, and deaths-United States, 2007 and 2013, vol 66 MMWR. Surveillance Summaries

109. Teo HT, Cabibihan JJ (2015) Toward soft, robust robots for children with autism spectrum disorder. In: FinE-R@ IROS, pp 15-19

110. Versace J (1971) A review of the severity index. Technical report, SAE Technical Paper

111. Willinger R, Baumgartner D (2003) Human head tolerance limits to specific injury mechanisms. Int J Crashworth 8(6):605-617

112. Wu JZ, Pan CS, Wimer BM, Rosen CL (2017) Finite element simulations of the head-brain responses to the top impacts of a construction helmet: Effects of the neck and body mass. Proceedings of the Institution of Mechanical Engineers, Part H: Journal of engineering in medicine 231(1):58-68

113. Wykowska A, Kajopoulos J, Obando-Leiton M, Chauhan SS, Cabibihan JJ, Cheng G (2015) Humans are well tuned to detecting agents among non-agents: Examining the sensitivity of human perception to behavioral characteristics of intentional systems. Int J Soc Robot 7(5):767-781

114. Yamada Y, Hirasawa Y, Huang S, Umetani Y (1996) Fail-safe human/robot contact in the safety space. In: 5th IEEE International Workshop on Robot and Human Communication, 1996, pp 59-64. IEEE

115. Yang NH, Rodowicz KA, Dainty D (2014) Baseball head impacts to the non-helmeted and helmeted hydrid III ATD. In: ASME 2014 International Mechanical Engineering Congress and Exposition, pp V003T03A007-V003T03A007. American Society of Mechanical Engineers

116. Yeates KO, Swift E, Taylor HG, Wade SL, Drotar D, Stancin T, Minich N (2004) Short and long-term social outcomes following pediatric traumatic brain injury. J Int Neuropsychol Soc 10(3):412-426

117. Young TJ, Daniel RW, Rowson S, Duma SM (2014) Head impact exposure in youth football: Elementary school ages 7-8 years and the effect of returning players. Clin J Sport Med 24(5):416-421

118. Zablotsky B, Black LI, Maenner MJ, Schieve LA, Blumberg SJ (2015) Estimated prevalence of autism and other developmental disabilities following questionnaire changes in the 2014 national health interview survey. Nat Health Stat Reports 87:1-21

119. Zhang L, Yang KH, King AI (2004) A proposed injury threshold for mild traumatic brain injury. Trans Am Soc Mech Eng J Biomech Eng 126(2):226-236

120. Zwaigenbaum L, Bryson S, Rogers T, Roberts W, Brian J, Szatmari P (2005) Behavioral manifestations of autism in the first year of life. Int J Dev Neurosci 23(2-3):143-152

Publisher's Note Springer Nature remains neutral with regard to jurisdictional claims in published maps and institutional affiliations.
Ahmad Yaser Alhaddad obtained his Bachelor degree in robotics and automation from Multimedia University (MMU), Malaysia in 2011; and obtained his Master degree in Mechatronics and Automatic Control from Universiti Teknologi Malaysia (UTM), Malaysia in 2013. He has worked on many engineering projects involving circuit design, microcontroller and control systems. He is currently doing his $\mathrm{PhD}$ in Mechanical and Information technology at Qatar University and at Politecnico di Milano, as part of the double doctorate programme. His research interests include social robotics, haptics, control and mechatronic systems.

John-John Cabibihan received the Ph.D. degree in bioengineering, with specialization in biorobotics, from the Scuola Superiore Sant'Anna, Pisa, Italy, in 2007. From 2008 to 2013, he was an Assistant Professor at the Electrical and Computer Engineering Department, National University of Singapore. He is currently an Associate Professor at the Mechanical and Industrial Engineering Department, Qatar University. He is Lead/Co-Lead Principal Investigator of several projects under the National Priorities Research Program of Qatar National Research Fund. He was the General Chair of the 10th International Conference on Social Robotics (ICSR) 2018 in Qingdao, China; Program Chair of ICSR 2012 in Chengdu, China, and ICSR 2016 in Kansas City, USA; and Program Co-Chair of ICSR 2010 (Singapore) and ICSR 2017 (Tsukuba, Japan). Over the years, his work has been focused toward assistive and social robotics for the therapy of children with autism, lifelike prosthetics, bioinspired tactile sensing, and human-robotic touch and gestures.

Andrea Bonarini is full professor and coordinator of the AI and Robotics Lab at Politecnico di Milano. His current research interests are on machine learning and emotional human-robot interaction, with special focus on robotic games and toys for entertainment and social, pshycological and physical development of people with and without special needs. Since 1989, he has developed with his collaborators and students more than 50 autonomous robots. In 2015, he co-founded Nova Labs, to share experience and tools to produce professional robots in a short time at low cost. He is collaborating with toy companies to introduce technology in their products. He has an active role in the COST European network "LUDI: play for children with disabilities". He published more than 150 peer-reviewed papers. 